\title{
The association between tumor's location and cervical lymph nodes metastasis in papillary thyroid cancer
}

\author{
Ting-Ting Zhang ${ }^{1,2 \#}$, Xiu-Zhu $\mathrm{Qi}^{2,3 \#}$, Jian-Ping Chen ${ }^{4 *}$, Rong-Liang Shi ${ }^{1,2}$, Shi-Shuai Wen ${ }^{1,2}$, \\ Yu-Long Wang ${ }^{1,2}$, Qing-Hai Ji ${ }^{1,2}$, Qiang Shen ${ }^{1,2}$, Yong-Xue Zhu ${ }^{1,2}$, Ning Qu ${ }^{1,2}$ \\ ${ }^{1}$ Department of Head and Neck Surgery, Fudan University Shanghai Cancer Center, Shanghai 200032, China; ${ }^{2}$ Department of Oncology, Shanghai \\ Medical College, Fudan University, Shanghai 200032, China; ${ }^{3}$ Department of Ultrasonography, Fudan University Shanghai Cancer Center, Shanghai \\ 200032, China; ${ }^{4}$ Department of Breast and Thyroid Surgery, Yijishan Hospital of Wannan Medical College, Wuhu 241001, China \\ Contributions: (I) Conception and design: TT Zhang, XZ Qi, Q Shen, YX Zhu, N Qu; (II) Administrative support: RL Shi, YL Wang, QH Ji; (III) \\ Provision of study materials or patients: JP Chen, SS Wen, Q Shen; (IV) Collection and assembly of data: JP Chen, SS Wen, XZ Qi; (V) Data \\ analysis and interpretation: TT Zhang, XZ Qi, N Qu; (VI) Manuscript writing: All authors; (VII) Final approval of manuscript: All authors. \\ \#These authors contributed equally to this work. \\ Correspondence to: Prof. Qiang Shen; Prof. Yong-Xue Zhu; Prof. Ning Qu. Department of Head and Neck Surgery, Fudan University Shanghai \\ Cancer Center; Department of Oncology, Shanghai Medical College, Fudan University, Dongan Road 270, Xuhui, Shanghai 200032, China. \\ Email: shenqiang_fuscc@163.com; zhuyongxuelb@icloud.com; jonathan_qn@163.com.
}

Background: Papillary thyroid cancer (PTC) has a strong propensity to metastasize to the cervical lymph nodes. Little was known currently about whether tumor's location would influence the risk of lymph node metastasis in PTC.

Methods: The study enrolled PTC patients who underwent primary surgical therapy in our center for small unifocal tumor. The tumor's location was evaluated by ultrasound in three axes, three planes and 3D space. Logistic univariate and multivariate analysis were applied to explore the association between tumors' location and the risk of lymph node metastasis in PTC. Different localization methods of thyroid tumors were evaluated using ROC curve.

Results: Totally 1,266 PTC patients were enrolled in this study. Univariate and multivariate analyses showed that gender, age, tumor size and tumor's location (in longitudinal axis, longitudinal sagittal plane, longitudinal coronal plane, sagittal coronal plane and 3D space) was associated with central lymph node dissection (CLND); gender, tumor size and tumor's location (in longitudinal axis, coronal axis, longitudinal sagittal plane, longitudinal coronal plane, sagittal coronal plane and 3D space) was related with lateral lymph node dissection (LLND) $(\mathrm{P}<0.05)$. In the ROC curve analysis, the 3D location showed the highest predictive value of lymph node metastasis (C-statistics: 0.724 for CLNM; 0.763 for LLNM). The middle posterior lateral $(\mathrm{OR}=2.575, \mathrm{P}=0.028)$, inferior anterior central $(\mathrm{OR}=2.829, \mathrm{P}=0.016)$, inferior posterior lateral $(\mathrm{OR}=2.759, \mathrm{P}=0.039)$ and isthmus tumors $(\mathrm{OR}=4.526, \mathrm{P}=0.001)$ were at a higher risk of CLNM, and the middle anterior central tumors $(\mathrm{OR}=0.102, \mathrm{P}=0.015)$ were related with lower risk of LLNM.

Conclusions: Stereotactic localization showed the highest predictive value of lymph node metastasis. The middle posterior lateral, inferior anterior central, inferior posterior lateral and isthmus tumors were at a higher risk of CLNM when compared to other locations. For such patients, careful preoperative evaluation of nodal status should be done.

Keywords: Papillary thyroid cancer (PTC); tumor's location; lymph node metastasis; predictive factor; ultrasound

Submitted Sep 09, 2019. Accepted for publication Sep 27, 2019.

doi: 10.21037 /gs.2019.10.02

View this article at: http://dx.doi.org/10.21037/gs.2019.10.02

(c) Gland Surgery. All rights reserved. 


\section{Introduction}

Papillary thyroid cancer (PTC) always have a favorable prognosis, but with the risk of cervical lymph nodes metastasis and regional recurrence $(1,2)$. The incidence of cervical lymph node metastasis in patients with PTC is about $30-80 \%(3-7)$. As reported, the lymph node metastasis usually has little impacts on survival, but it would increase the risk of postoperative recurrence (8). It's reported also that cervical lymph node metastases are associated with compromised survival in young patients (9). Therefore, preoperative assessment of the risk of lymph node metastasis is essential for guiding treatment. Many characteristics have been identified as the risk factors of lymph node metastasis for PTC, such as gender, age, extrathyroid invasion, etc. $(8,10-13)$.

The location of thyroid nodules was reported to be associated with lymph node metastasis in PTC. Hunt et al. (14) reported that tumor in the superior aspect of the thyroid lobe has a higher risk of lateral cervical metastasis. However, Lee et al. (15) supported that the risk of central and lateral cervical lymph node metastasis was higher in PTC patients with posterosuperior lesion. Currently, little is known about the association between the location of PTC and the risk of lymph node metastasis. Therefore, this study is intended to explore the association between tumor's location and the risk of lymph nodes metastasis in PTC.

\section{Methods}

\section{Patients}

The medical records of all PTC patients who underwent surgery by one experienced surgeon (Dr. Qiang Shen) in the department of head \& neck surgery in Fudan University Shanghai Cancer Center between January 1, 2011 and December 31, 2017 were reviewed retrospectively. All patients provided written informed consent for their information to be stored in the hospital database and used for research, and this study was approved by the Ethical Committee of Fudan University Shanghai Cancer Center (ID: JS170). Of all 4,382 patients, 3,116 patients were excluded according to our inclusion/exclusion criterion: 320 patients with previous thyroid surgery, 523 patients underwent non-thyroid surgery, 357 patients with incomplete imaging data, 101 patients with inconsistent results between preoperative imaging and pathological examinations, 733 patients with benign pathological tumors, 501 patients with large size tumors that are difficult to evaluate the ultrasonic partition, 536 patients with multifocal tumors, 13 patients with pathology of nonpapillary thyroid carcinoma and 32 patients with obscure evaluation for nodal metastasis by current system of 6 levels in pathology. Finally, 1,266 patients were enrolled in this research. A cohort of 1,266 consecutive PTC patients who underwent primary surgical therapy for unifocal tumor with complete clinical, pathological, and imaging data were enrolled in this study.

\section{Initial treatment}

Before surgery, each patient underwent an ultrasonography (US) and enhanced cervical CT examination. US-guided fine-needle aspiration (FNA) was not performed routinely. Lobectomy plus ipsilateral central lymph node dissection (CLND) was typically performed as the initial surgical treatment for PTC patients with malignant lesions limited to a single lobe. Total thyroidectomy (TT) or near total thyroidectomy (nTT) was performed at the time of the initial operation when the condition is as following: the primary tumor $>1 \mathrm{~cm}$, undetermined nodules in the contralateral lobe by US, regional metastases or multifocal tumors. Histology of the frozen sections (FS) assisted surgeons in determining the extent of the surgical procedures. Selective lateral lymph node dissection (LLND), including levels II-V, was performed in cases with pathologically proven lateral lymph node metastasis or suspicious lymph nodes observed intraoperatively or on preoperative imaging.

\section{The location of thyroid nodules}

The location of the thyroid nodules was estimated by preoperative ultrasonography. One ultrasonologist who did not know about the pathological results estimated all ultrasound findings. According to the ultrasonography, the thyroid glands were divided into different portions (Figure 1). Since there is no clear anatomical division, the thyroid glands are bisected in the three axes. When the nodules were occupied two or more than two portions, the location was determined based on the majority or the center of the nodules. The large tumors that were difficult to evaluate the ultrasonic location were excluded from this study.

\section{Statistical analysis}

Statistical analyses were performed using SPSS ver. 22.0 (SPSS Inc., Chicago, IL, USA). Patient characteristics 

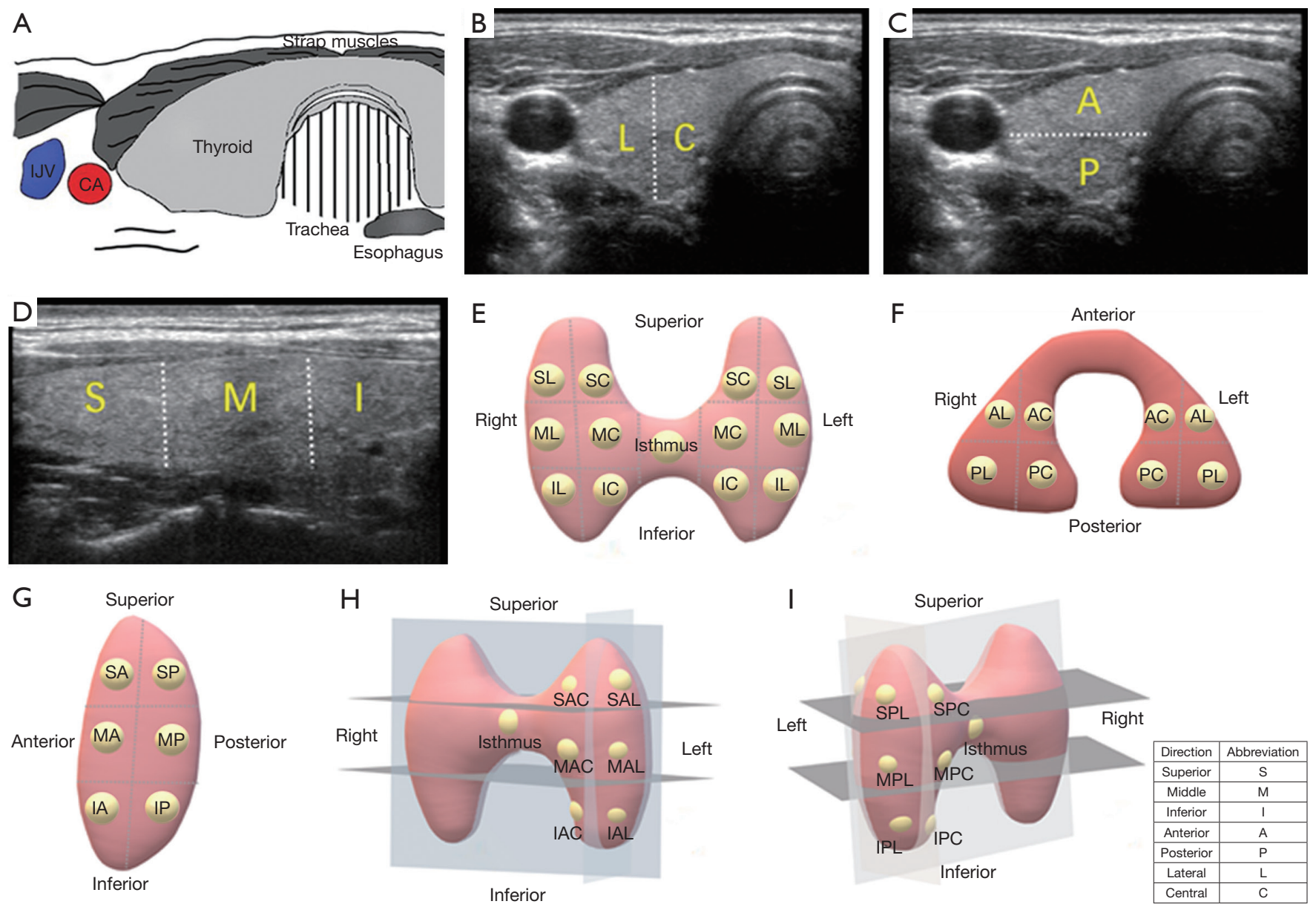

Figure 1 Ultrasonographic views of thyroid gland and different localization methods of PTC tumors. (A) Diagram of thyroid anatomy; (B) in the longitudinal view, the gland was divided into superior $(\mathrm{S})$, middle $(\mathrm{M})$, and inferior (I) positions; $(\mathrm{C})$ in the coronal view, the gland was divided into lateral (L) and central (C) positions; (D) in the sagitta view, the gland was divided into anterior (A) and posterior (P) positions; (E) longitudinal coronal location. The gland was divided into superior central (SC), superior lateral (SL), middle central (MC), middle lateral (ML), inferior central (IC), inferior lateral (IL) and isthums positions; (F) longitudinal sagittal location. The gland was divided into superior anterior (SA), superior posterior (SP), middle anterior (MA), middle posterior (MP), inferior anterior (IA), inferior posterior (IP) and isthmus positions. (G) Sagittal coronal location. The gland was divided into anterior central (AC), anterior lateral (AL), posterior central (PC), posterior lateral (PL) and isthmus positions; (H) 3D location in anteroposterior view. The superior anterior central (SAC), superior anterior lateral (SAL), middle anterior central (MAC), middle anterior lateral (MAL), inferior anterior central (IAC), inferior anterior lateral (IAL) and isthmus positions were shown; (I) 3D location in posteroanterior view. The superior posterior central (SPC), superior posterior lateral (SPL), middle posterior central (MPC), middle posterior lateral (MPL), inferior posterior central (IPC), inferior posterior lateral (IPL) and isthmus positions were shown. IJV, internal jugular vein; CA, carotid artery.

were compared using the chi-square test for categorical variables and Student's $t$-test for continuous variables. The relationship between several clinicopathologic factors and the risk of lymph node metastasis was assessed. Among the factors, the location of tumor was analyzed in three axes, three two-dimensional (2D) planes and one three- dimensional (3D) space. We performed a logistic regression multivariate analysis that included the risk factors which had a significant relationship with lymph node metastasis in the univariate analysis. A $\mathrm{P}$ value $<0.05$ was considered significant. Receiver operating characteristic (ROC) curve and the C-statistics was used to evaluate the accuracy of 
Table 1 Characteristics of the cohort

\begin{tabular}{|c|c|c|}
\hline Characteristics & $N=1,266$ & $\%$ \\
\hline \multicolumn{3}{|l|}{ Gender } \\
\hline Male & 326 & 25.8 \\
\hline Female & 940 & 74.2 \\
\hline \multicolumn{3}{|l|}{ Age } \\
\hline$\leq 55$ years & 1,058 & 83.6 \\
\hline$>55$ years & 208 & 16.4 \\
\hline \multicolumn{3}{|l|}{ Hashimoto's disease } \\
\hline Yes & 261 & 20.6 \\
\hline No & 1,005 & 79.4 \\
\hline \multicolumn{3}{|l|}{ Goiter } \\
\hline Yes & 118 & 9.3 \\
\hline No & 1,148 & 90.7 \\
\hline \multicolumn{3}{|l|}{ Capsule invasion } \\
\hline No & 1,207 & 95.3 \\
\hline Yes & 59 & 4.7 \\
\hline \multicolumn{3}{|l|}{ Tumor size } \\
\hline$\leq 1 \mathrm{~cm}$ & 396 & 31.3 \\
\hline $1-1.5 \mathrm{~cm}$ & 601 & 47.5 \\
\hline $1.5-2 \mathrm{~cm}$ & 224 & 17.7 \\
\hline$>2 \mathrm{~cm}$ & 45 & 3.6 \\
\hline \multicolumn{3}{|l|}{ Surgery } \\
\hline Lobectomy & 1,049 & 82.9 \\
\hline Total thyroidectomy & 95 & 7.5 \\
\hline Near total thyroidectomy & 122 & 9.6 \\
\hline \multicolumn{3}{|l|}{ Lateral neck dissection } \\
\hline Yes & 75 & 5.9 \\
\hline No & 1,191 & 94.1 \\
\hline \multicolumn{3}{|l|}{ CLNM } \\
\hline No & 815 & 64.4 \\
\hline Yes & 451 & 35.6 \\
\hline \multicolumn{3}{|l|}{ LLNM } \\
\hline No & 1,210 & 95.6 \\
\hline Yes & 56 & 4.4 \\
\hline
\end{tabular}

CLNM, central lymph node metastasis; LLNM, lateral lymph node metastasis. different localization methods.

\section{Results}

\section{Characteristics of the study cohort}

As shown in Table 1, 1,266 PTC patients were enrolled in this study. The cohort consists of 326 males and 940 females, of whom 1,058 patients $(83.6 \%)$ were $\leq 55$ years old. Among the cohort, 261 PTC patients (20.6\%) were accompanied with Hashimoto's disease and 118 patients (9.3\%) with goiter. Extrathyroidal extension occurred in 59 patients (4.7\%). All 1,266 patients were pathologically diagnosed as PTC. There were 997 patients (78.8\%) with papillary thyroid microcarcinoma (PTMC), and totally 1,221 patients (96.4\%) with tumor smaller than $1.5 \mathrm{~cm}$. All 1,266 patients underwent central lymph node dissection (CLND), and 75 patients $(5.9 \%)$ of them underwent lateral lymph node dissection further. Central lymph node metastasis (CLNM) occurred in 451 patients $(35.6 \%)$, and lateral lymph node metastasis (LLNM) in 56 patients $(4.4 \%)$. After a mean 18.1 months of follow-up, 11 patients $(0.87 \%)$ occurred regional recurrence. No patient died or had distant metastasis during follow-up.

\section{Central lymph node metastasis}

In the univariate analysis, female $(\mathrm{OR}=0.465, \mathrm{P}<0.001)$ and the patients $>55$ years old $(\mathrm{OR}=0.312, \mathrm{P}<0.001)$ had less risk of CLNM, and tumor size was also related with CLNM $(\mathrm{OR}=2.039, \mathrm{P}<0.001)$ (Table 2). Hashimoto's disease, goiter and capsule invasion wasn't related with CLNM $(\mathrm{P}>0.05)$. The tumors in the inferior portion and isthmus were at higher risk of CLNM in the longitudinal axis (the inferior portion: $\mathrm{OR}=1.478, \mathrm{P}=0.034$; isthmus: $\mathrm{OR}=2.679, \mathrm{P}<0.001$ ). There was no difference between different portions in sagittal and coronal axis. In the longitudinal sagittal plane, inferior anterior tumors and isthmus tumors were related with CLNM (inferior anterior tumors: $\mathrm{OR}=1.692, \mathrm{P}=0.033$; isthmus: $\mathrm{OR}=2.828, \mathrm{P}=0.001)$. Compared with superior central nodules in the longitudinal coronal plane, lateral superior nodules $(\mathrm{OR}=1.937, \mathrm{P}=0.049)$, middle central nodules $(\mathrm{OR}=1.882, \mathrm{P}=0.044)$, middle lateral nodules $(\mathrm{OR}=2.056, \mathrm{P}=0.021)$, inferior central nodules $(\mathrm{OR}=2.383$, $\mathrm{P}=0.007)$, inferior lateral nodules $(\mathrm{OR}=2.355, \mathrm{P}=0.014)$ and isthmus nodules $(\mathrm{OR}=4.300, \mathrm{P}<0.001)$ all showed a higher risk of CLNM. In the sagittal coronal plane, isthmus 
Table 2 Analysis of risk factors for central lymph node metastasis in papillary thyroid cancer (PTC)

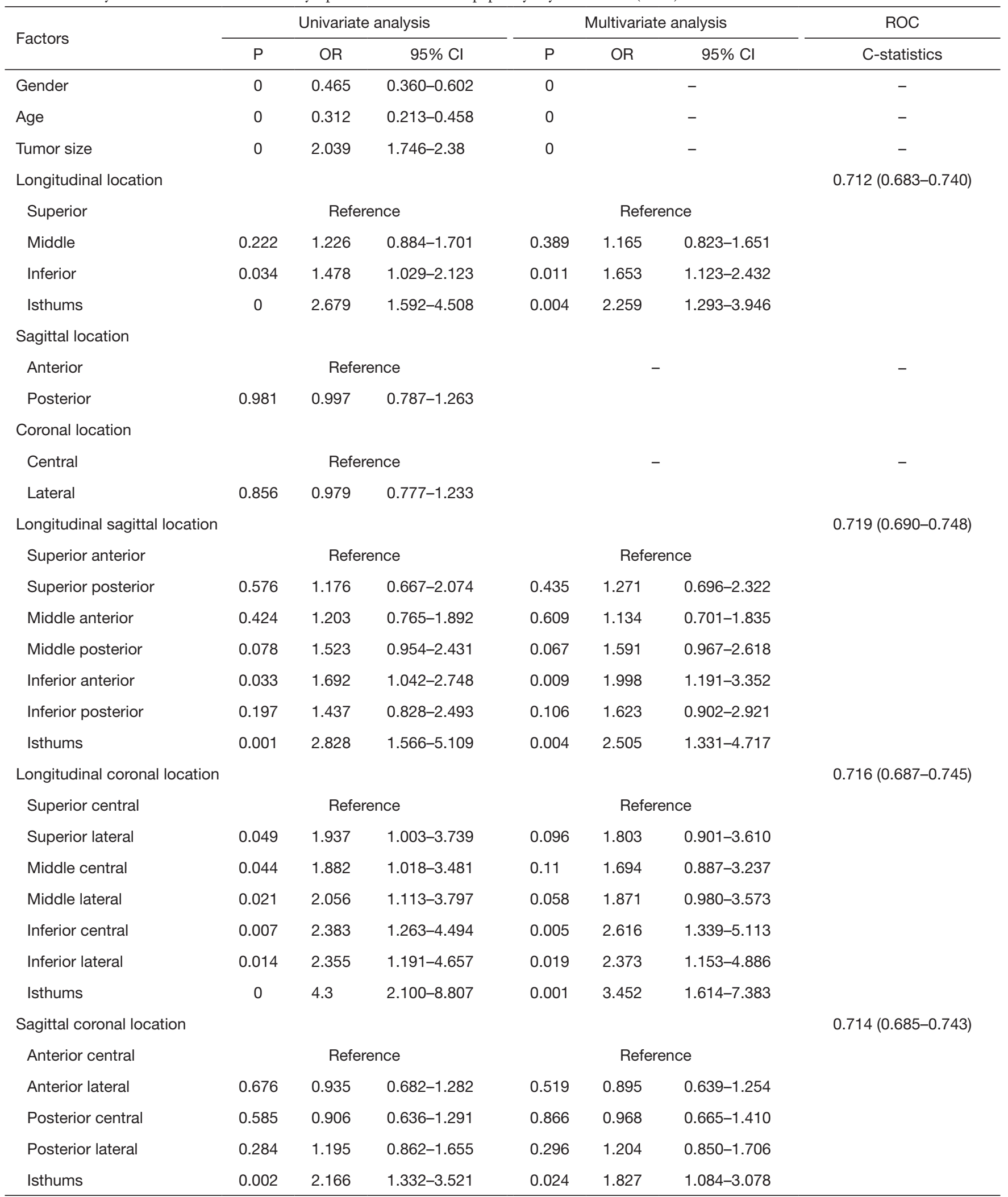

Table 2 (continued) 
Table 2 (continued)

\begin{tabular}{|c|c|c|c|c|c|c|c|}
\hline Factors & \multicolumn{3}{|c|}{ Univariate analysis } & \multicolumn{3}{|c|}{ Multivariate analysis } & $\frac{\mathrm{ROC}}{\text { C-statistics }}$ \\
\hline 3D location & & & & & & & $0.724(0.696-0.753)$ \\
\hline Superior anterior central & \multicolumn{3}{|c|}{ Reference } & \multicolumn{3}{|c|}{ Reference } & \\
\hline Superior anterior lateral & 0.167 & 1.891 & $0.765-4.671$ & 0.19 & 1.895 & $0.729-4.924$ & \\
\hline Superior posterior lateral & 0.087 & 2.204 & $0.891-5.454$ & 0.092 & 2.277 & $0.875-5.927$ & \\
\hline Middle anterior central & 0.133 & 1.893 & $0.824-4.348$ & 0.217 & 1.737 & $0.723-4.172$ & \\
\hline Middle anterior lateral & 0.144 & 1.867 & $0.808-4.312$ & 0.185 & 1.818 & $0.752-4.398$ & \\
\hline Middle posterior central & 0.086 & 2.123 & $0.900-5.010$ & 0.068 & 2.322 & $0.939-5.745$ & \\
\hline Inferior anterior lateral & 0.079 & 2.286 & $0.908-5.752$ & 0.081 & 2.386 & $0.898-6.341$ & \\
\hline Inferior posterior central & 0.174 & 1.909 & $0.751-4.853$ & 0.141 & 2.096 & $0.783-5.609$ & \\
\hline Inferior posterior lateral & 0.039 & 2.759 & $1.055-7.217$ & 0.023 & 3.273 & $1.177-9.106$ & \\
\hline Isthums & 0.001 & 4.526 & $1.860-11.013$ & 0.004 & 3.962 & $1.546-10.153$ & \\
\hline
\end{tabular}

tumors were statistically associated with CLNM $(\mathrm{OR}=2.166$, $\mathrm{P}=0.002)$. For the $3 \mathrm{D}$ location, middle posterior lateral nodules $(\mathrm{OR}=2.575, \mathrm{P}=0.028)$, inferior anterior central nodules $(\mathrm{OR}=2.829, \mathrm{P}=0.016)$, inferior posterior lateral nodules $(\mathrm{OR}=2.759, \mathrm{P}=0.039)$ and isthmus nodules ( $\mathrm{OR}=4.526, \mathrm{P}=0.001)$ were related with $\mathrm{CLNM}$.

Multivariate analysis was performed to reveal the association between gender, age, tumor size, tumors' location in different planes and CLNM (Table 2). In all five analysis, gender, age and tumor size was related with CLNM. In the multivariate analysis of gender, age, tumor size and longitudinal location, the tumors in the inferior portion $(\mathrm{OR}=1.653, \mathrm{P}=0.011)$ and isthmus $(\mathrm{OR}=2.259$, $\mathrm{P}=0.004)$ were at higher risk of CLNM. Inferior anterior tumors $(\mathrm{OR}=1.998, \mathrm{P}=0.009)$ and isthmus tumors $(\mathrm{OR}=2.505, \mathrm{P}=0.004)$ were related with CLNM in the multivariate analysis of longitudinal sagittal location. For longitudinal coronal location, inferior central nodules $(\mathrm{OR}=2.616, \mathrm{P}=0.005)$ and isthmus nodules $(\mathrm{OR}=3.452$, $\mathrm{P}=0.001)$ showed a higher risk of CLNM compared with superior central nodules. In the sagittal coronal plane, isthmus tumors were statistically associated with CLNM $(\mathrm{OR}=1.827, \mathrm{P}=0.024)$. For the $3 \mathrm{D}$ location, middle posterior lateral $(\mathrm{OR}=2.618, \mathrm{P}=0.034)$, inferior anterior central
$(\mathrm{OR}=3.555, \mathrm{P}=0.005)$, inferior posterior lateral $(\mathrm{OR}=3.273$, $\mathrm{P}=0.023)$ and isthmus $(\mathrm{OR}=3.962, \mathrm{P}=0.004)$ nodules were related with CLNM. The ROC curves were analyzed for the five methods of location classification and CLNM in the multivariate analysis. As results, the $3 \mathrm{D}$ location showed the highest predictive value, of which the C-statistics was 0.724 (0.696-0.753) (Figure 2A). The nomogram and calibration curve of the $3 \mathrm{D}$ localization was shown in Figure $2 B$ and $2 C$.

\section{Lateral cervical lymph node metastasis}

In the univariate analysis, gender $(\mathrm{OR}=0.562, \mathrm{P}=0.042)$ and tumor size $(\mathrm{OR}=1.848, \mathrm{P}<0.001)$ was related with LLNM (Table 3). Age, Hashimoto's disease, goiter and capsule invasion wasn't related with CLNM $(\mathrm{P}>0.05)$. The middle and inferior tumors in the longitudinal axis were at lower risk of LLNM (the middle: OR=0.405, $\mathrm{P}=0.003$; the inferior: $\mathrm{OR}=0.254, \mathrm{P}=0.001$ ), and the lateral tumors in coronal axis were at higher risk of LLNM $(\mathrm{OR}=2.306, \mathrm{P}=0.004)$. There was no difference between different portions in sagittal axis and longitudinal coronal plane $(\mathrm{P}>0.05)$. In the longitudinal sagittal plane, inferior anterior tumors were related with decreased risk of LLNM $(\mathrm{OR}=0.276, \mathrm{P}=0.022)$. In the sagittal coronal plane, isthmus 

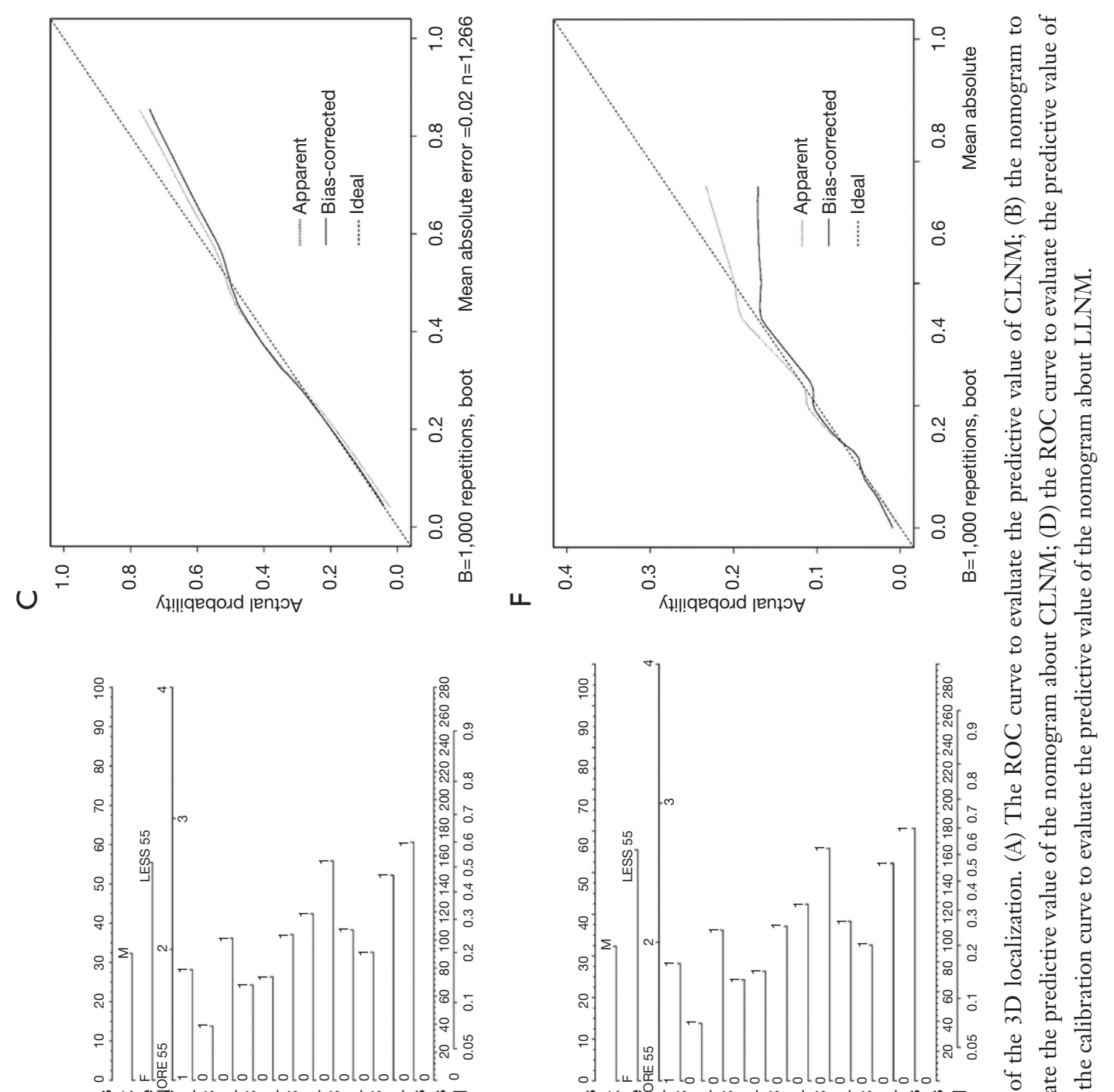

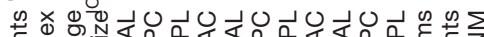
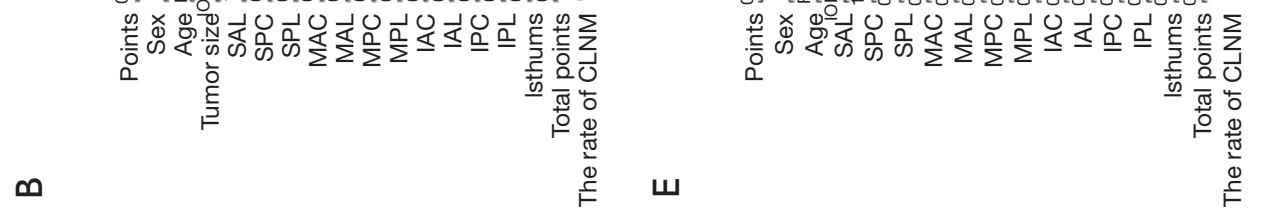

ш
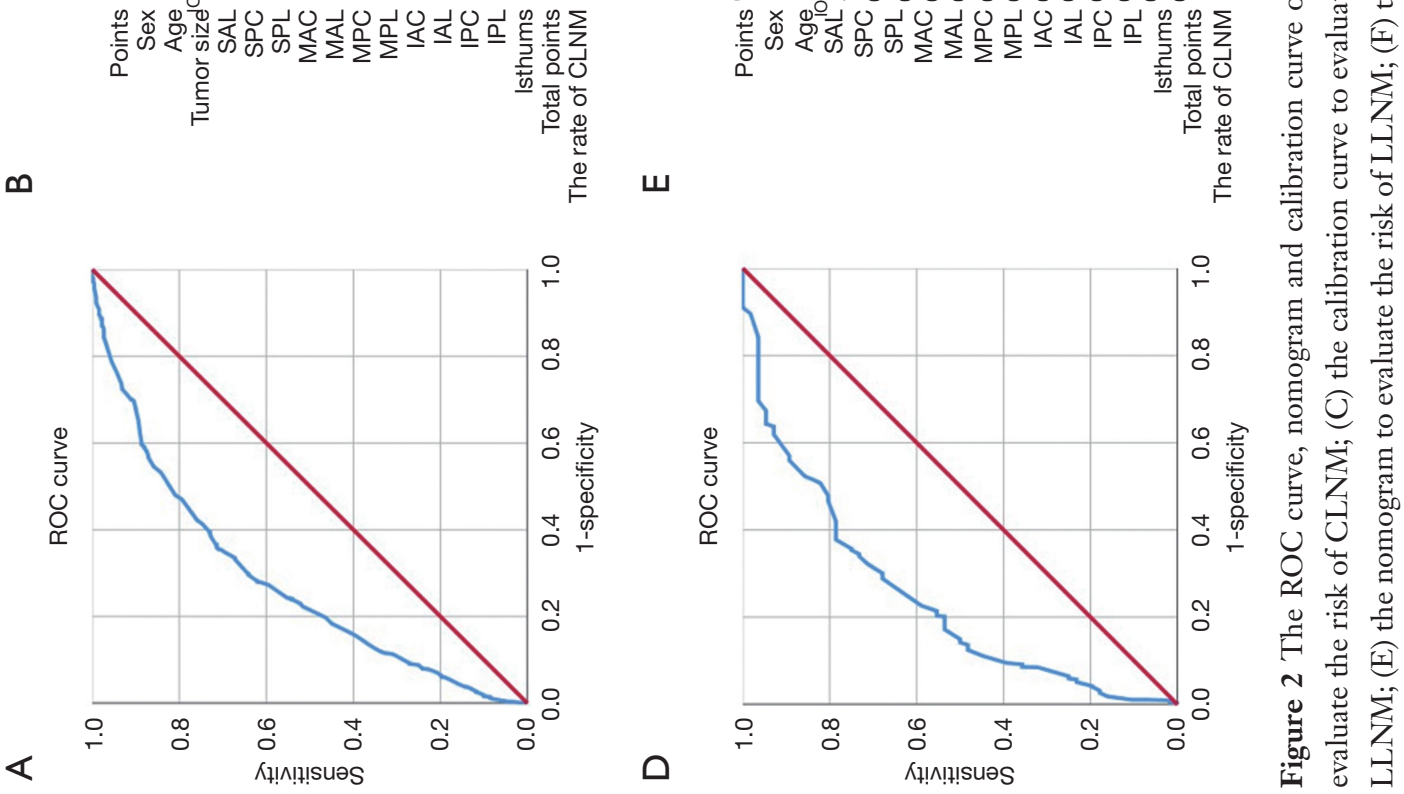

䒕

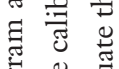

क人

घ)

$\dot{s} \ddot{\Sigma}$

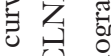
ن $\leadsto$ 我 ข. ज्ञ Fิ ৩

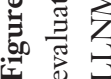


Table 3 Analysis of risk factors for lateral lymph node metastasis in papillary thyroid cancer (PTC)

\begin{tabular}{|c|c|c|c|c|c|c|c|}
\hline Factors & \multicolumn{3}{|c|}{ Univariate analysis } & \multicolumn{3}{|c|}{ Multivariate analysis } & $\frac{\mathrm{ROC}}{\text { C-statistics }}$ \\
\hline Gender & 0.042 & 0.562 & $0.322-0.98$ & 0 & & - & \\
\hline Tumor size & 0 & 1.848 & $1.35-2.53$ & 0 & & - & \\
\hline Longitudinal location & & & & & & & $0.703(0.635-0.771)$ \\
\hline Inferior & 0.001 & 0.254 & $0.110-0.584$ & 0.001 & 0.254 & $0.110-0.589$ & \\
\hline Isthums & 0.066 & 0.251 & $0.057-1.094$ & 0.028 & 0.187 & $0.042-0.833$ & \\
\hline \multicolumn{8}{|l|}{ Sagittal location } \\
\hline Central & \multicolumn{3}{|c|}{ Reference } & \multicolumn{3}{|c|}{ Reference } & \\
\hline Lateral & 0.004 & 2.306 & $1.311-4.056$ & 0.005 & 2.252 & $1.275-3.978$ & \\
\hline Longitudinal sagittal location & & & & & & & $0.707(0.639-0.774)$ \\
\hline Superior anterior & \multicolumn{3}{|c|}{ Reference } & \multicolumn{3}{|c|}{ Reference } & \\
\hline Superior posterior & 0.616 & 1.259 & $0.512-3.092$ & 0.493 & 1.377 & $0.552-3.432$ & \\
\hline Middle anterior & 0.074 & 0.47 & $0.205-1.077$ & 0.046 & 0.423 & $0.182-0.983$ & \\
\hline Middle posterior & 0.068 & 0.43 & $0.174-1.063$ & 0.062 & 0.418 & $0.167-1.045$ & \\
\hline Inferior anterior & 0.022 & 0.276 & $0.092-0.828$ & 0.028 & 0.29 & $0.096-0.877$ & \\
\hline Middle central & 0.091 & 0.328 & $0.090-1.194$ & 0.044 & 0.26 & $0.070-0.964$ & \\
\hline Middle lateral & 0.896 & 1.077 & $0.355-3.267$ & 0.778 & 0.85 & $0.275-2.628$ & \\
\hline Inferior central & 0.428 & 0.601 & $0.171-2.117$ & 0.371 & 0.56 & $0.157-1.995$ & \\
\hline Inferior lateral & 0.092 & 0.149 & $0.016-1.362$ & 0.064 & 0.122 & $0.013-1.131$ & \\
\hline Isthums & 0.339 & 0.43 & $0.076-2.423$ & 0.162 & 0.286 & $0.050-1.653$ & \\
\hline Sagittal coronal location & & & & & & & $0.682(0.652-0.712)$ \\
\hline Anterior central & \multicolumn{3}{|c|}{ Reference } & \multicolumn{3}{|c|}{ Reference } & \\
\hline Anterior lateral & 0.971 & 1.006 & $0.736-1.375$ & 0.717 & 0.941 & $0.678-1.307$ & \\
\hline Posterior central & 0.651 & 0.922 & $0.648-1.311$ & 0.89 & 0.974 & $0.675-1.406$ & \\
\hline Posterior lateral & 0.224 & 1.223 & $0.884-1.692$ & 0.253 & 1.219 & $0.868-1.713$ & \\
\hline Isthums & 0.002 & 2.115 & $1.302-3.437$ & 0.023 & 1.821 & $1.088-3.048$ & \\
\hline
\end{tabular}

Table 3 (continued) 
Table 3 (continued)

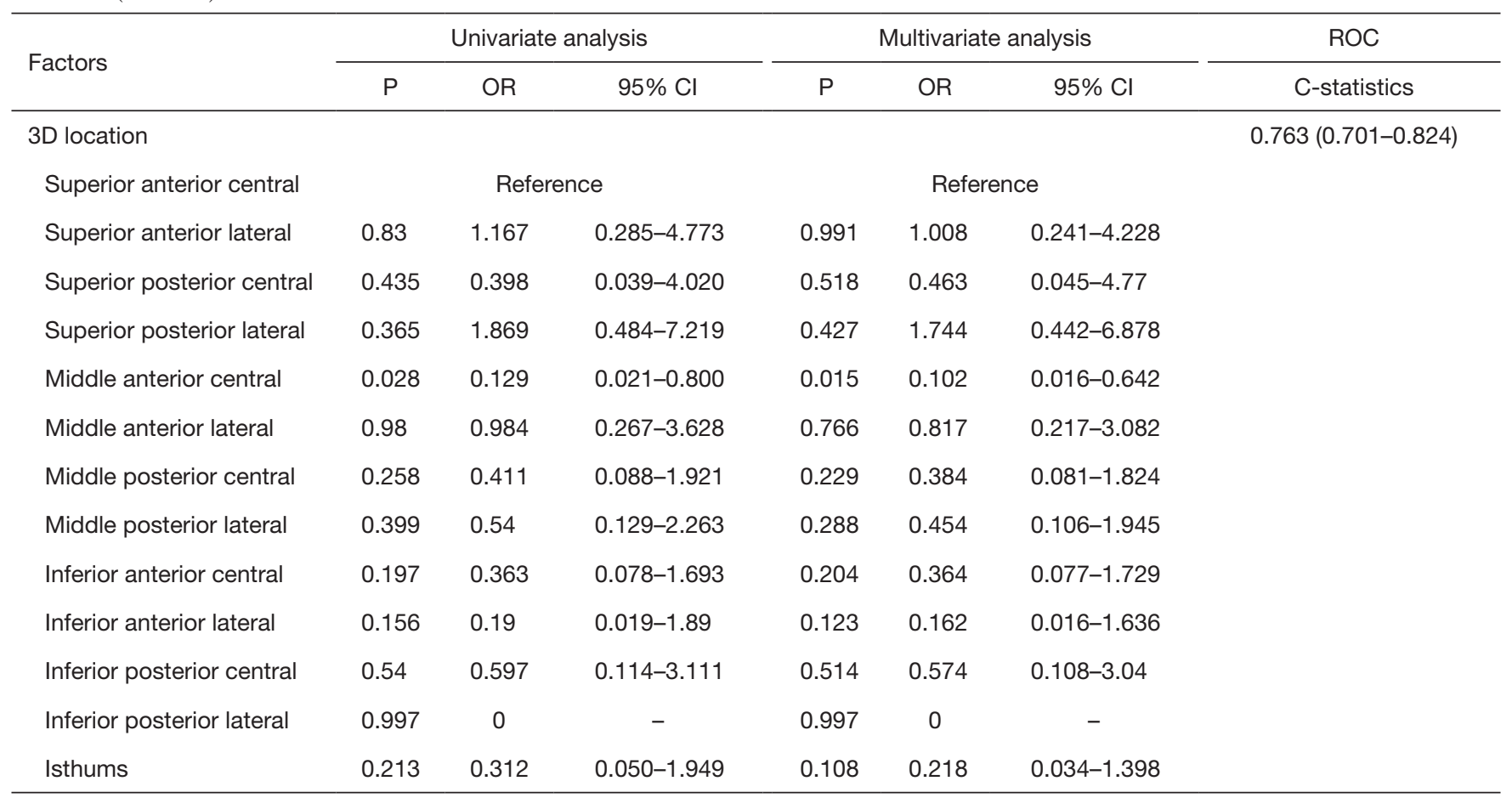

tumors were statistically associated with LLNM $(\mathrm{OR}=2.115$, $\mathrm{P}=0.002)$. For the $3 \mathrm{D}$ location, middle anterior central nodules $(\mathrm{OR}=0.129, \mathrm{P}=0.028)$ were at lower risk of LLNM.

Multivariate analysis was performed to explore further the association between gender, tumor size, tumors' location and LLNM (Table 3). In all six analysis, gender and tumor size was related with LLNM $(\mathrm{P}<0.05)$. In the multivariate analysis of gender, tumor size and longitudinal location, the tumors in the middle portion $(\mathrm{OR}=0.362$, $\mathrm{P}=0.001)$, the inferior portion $(\mathrm{OR}=0.254, \mathrm{P}=0.001)$ and the isthmus $(\mathrm{OR}=0.187, \mathrm{P}=0.028)$ were statistically associated with LLNM. In the coronal axis, lateral tumors were at higher risk of LLNM $(\mathrm{OR}=2.252, \mathrm{P}=0.005)$. Middle anterior tumors $(\mathrm{OR}=0.423, \mathrm{P}=0.046)$ and inferior anterior tumors $(\mathrm{OR}=0.290, \mathrm{P}=0.028)$ were related with $\mathrm{LLNM}$ in the multivariate analysis of longitudinal sagittal location. For longitudinal coronal location, middle central nodules $(\mathrm{OR}=0.260, \mathrm{P}=0.044)$ showed a lower risk of LLNM compared with superior central nodules. In the sagittal coronal plane, isthmus tumors were statistically associated with $\operatorname{LLNM}(\mathrm{OR}=1.821, \mathrm{P}=0.023)$. For the $3 \mathrm{D}$ location, middle anterior central nodules $(\mathrm{OR}=0.102, \mathrm{P}=0.015)$ were related with LLNM. The ROC curve and C-statistics were analyzed for the six methods of location classification and
LLNM in the multivariate analysis. The C-statistics of $3 \mathrm{D}$ location, as the highest one, was 0.763 (0.701-0.824) (Figure 2D). The nomogram and calibration curve of the 3D localization was shown in Figure 2E,F.

\section{Discussion}

PTC has a strong propensity to metastasize to central and lateral lymph nodes. Surgery is the optimal treatment for primary tumor and lymph node metastasis of PTC. Although the lymph node metastasis usually has little impacts on survival, but it would increase the risk of regional recurrence and reoperation $(1,2,8)$. Ultrasound plays an important role with high sensitivity and specificity in the preoperative evaluation of PTC. It could help distinguish the benign and malignant thyroid nodules and evaluate the lymph nodes metastasis $(16,17)$. Accurate preoperative assessment of lymph node metastasis is crucial to determine the surgical procedures. If some features of the primary tumor examined by ultrasound could act as the risk factors for lymph node metastasis, it will be beneficial for further treatment.

Many characteristics have been identified as the risk factors of lymph node metastasis in patients with PTC, such 

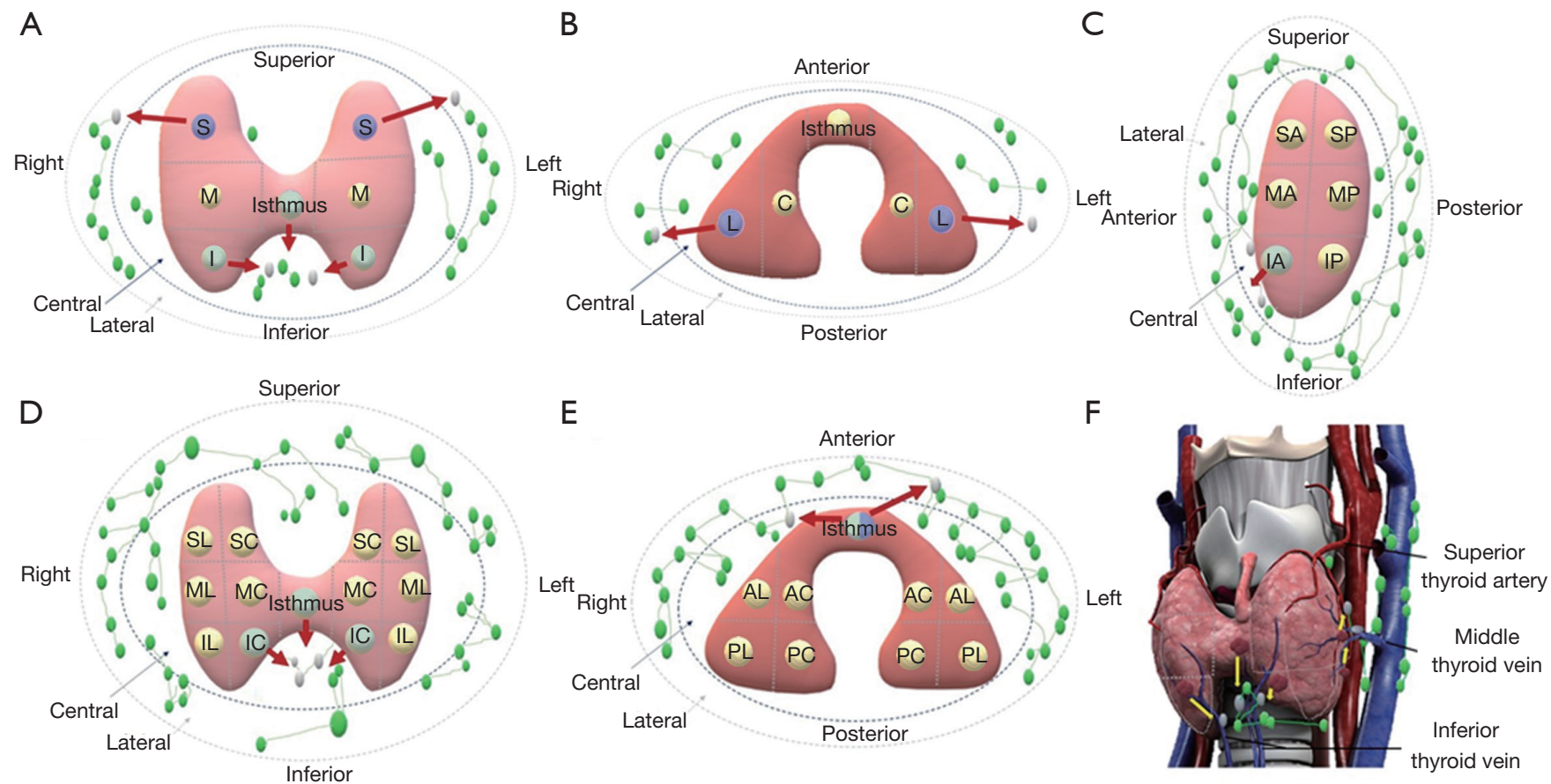

Figure 3 Patterns of lymph node metastasis in different views. (A) Longitudinal axis. The superior tumor is more likely to metastasize to the lateral region; the inferior and isthmus tumors are at higher risk of CLNM; (B) coronal axis. The lateral tumors are more prone to LLNM; (C) longitudinal sagittal plane. The inferior anterior tumors are at higher risk of CLNM; (D) longitudinal coronal plane. The inferior central and isthmus tumors are at higher risk of CLNM; (E) sagittal coronal plane. The risk of both CLNM and LLNM are higher for isthmus tumors; (F) 3D space. The medial inferior anterior, posterolateral middle, posterolateral inferior and isthmic tumors metastasize more easily to the central region.

as gender, age, extrathyroid invasion and lager tumor, etc. (7,10-13). The location of thyroid nodules was reported to be associated with lymph node metastasis in PTC, however, it is still controversial. The tumors in the upper lobes of the thyroid were reported to be at a higher risk of lateral cervical metastasis $(3,14)$. It has been reported that the tumors located in the upper pole of the thyroid could spread directly to the upper part of the ipsilateral lateral cervical lymph node $(18,19)$. Differently, Lee et al. (15) supported that the risk of central and lateral cervical lymph node metastasis was higher in PTC patients with posterosuperior lesion. Kwak et al. (20) showed that ultrasonographic feature of upper pole location have significant association with lateral nodal metastasis. Previous study from our center also showed that tumor location in the upper third of the thyroid lobe was associated with a lower risk of CLNM and a higher risk of LLNM (11). However, some studies have reported no significant association between tumor site and lymph node metastasis (21).

Previous studies enrolled heterogenous samples, such as multifocal, large tumors or recurrent cases, which could change the direction of lymphatic drainage. In addition, they all analyzed tumor's location on a linear or planar basis, without taking into account the $3 \mathrm{D}$ location of the tumor. Thus, the present study included only previously untreated PTC patients with unifocal and not too large tumor. Furthermore, the tumor's location was analyzed in three axes, three planes and one 3D space. As results, gender, age, tumor size and tumor's location were found to be associated with CLNM, and gender, tumor size and tumor's location was related with LLNM. In the ROC curve analysis, the 3D location showed the highest predictive value (C-statistics: 0.724 for CLNM; 0.763 for LLNM). The middle posterior lateral $(\mathrm{OR}=2.575, \mathrm{P}=0.028)$, inferior anterior central $(\mathrm{OR}=2.829, \mathrm{P}=0.016)$, inferior posterior lateral $(\mathrm{OR}=2.759$, $\mathrm{P}=0.039)$ and isthmus tumors $(\mathrm{OR}=4.526, \mathrm{P}=0.001)$ were at a higher risk of CLNM, and the middle anterior central tumors $(\mathrm{OR}=0.102, \mathrm{P}=0.015)$ were related with lower risk of LLNM.

To present the results more visually, the pattern diagrams 
of the risk of lymph node metastasis to the patients with thyroid nodules in different locations have been drawn (Figure 3). In the longitudinal axis, the superior nodule is more likely to metastasize to the lateral cervical region, while the inferior and isthmus tumors are at higher risk of CLNM. In the coronal axis, the lateral tumors are more prone to LLNM. The inferior anterior tumors in the longitudinal sagittal plane, inferior central and isthmus tumors in longitudinal coronal plane are at higher risk of CLNM. From a cross-sectional view, the risk of both CLNM and LLNM are higher for isthmus tumors. In the $3 \mathrm{D}$ space, the medial inferior anterior and isthmic nodules close to the inferior thyroid vein, as well as the posterolateral middle and posterolateral inferior nodules close to the middle thyroid vein, metastasize more easily to the central region. To simplify the results, the tumors in the more interior and lower pole of thyroid were at higher risk for metastasizing to the central lymph nodes, and the tumors in the upper pole are more likely to have lateral lymph node metastasis, even skipping lateral cervical metastasis. Moreover, we hypothesized that the risk of lymph node metastasis for PTC nodules at different locations might be associated with venous reflux.

Our study described the effects of the tumors' location on the risk of lymph node metastasis in PTC. This is the first study using different linear, planar and stereoscopic localization methods to explore the association between tumors' location and risk of lymph node metastasis. There are some limitations. To assess tumors' location accurately, the patients included in this study were all with small tumors, which may partly explain the low incidence of LLNM (4.4\%). Because of the small sample with LLNM, the analysis of tumor's location and LLNM may be influenced. Thus, we will report our result of further study about LLNM in the near future. Since there were no definitive landmarks, the division of thyroid glands into the portions might be different depending on the various shapes of thyroid glands and the subjective judgement of ultrasonologist. A prospective analysis with more advanced ultrasound is necessary still in the future.

\section{Acknowledgments}

Funding: This study was supported by grants from the National Natural Science Foundation of China (No. 81702649 to NQ, No. 81572622 and No. 81272934 to QHJ, Nos. 81472498 and 81772851 to YLW).

\section{Footnote}

Conflicts of Interest: The authors have no conflicts of interest to declare.

Ethical Statement: The authors are accountable for all aspects of the work in ensuring that questions related to the accuracy or integrity of any part of the work are appropriately investigated and resolved. All patients provided written informed consent for their information to be stored in the hospital database and used for research, and this study was approved by the Ethical Committee of Fudan University Shanghai Cancer Center (ID: JS170).

\section{References}

1. Sherman SI. Thyroid carcinoma. Lancet 2003;361:501-11.

2. Grebe SK, Hay ID. Thyroid cancer nodal metastases: biologic significance and therapeutic considera-tions. Surg Oncol Clin N Am 1996;5:43-63.

3. Jeon MJ, Chung MS, Kwon H, et al. Features of papillary thyroid microcarcinoma associated with lateral cervical lymph node metastasis. Clin Endocrinol (Oxf) 2017;86:845-51.

4. Viola D, Materazzi G, Valerio L, et al. Prophylactic central compartment lymph node dissection in papil-lary thyroid carcinoma: clinical implications derived from the first prospective randomized controlled single institution study. J Clin Endocrinol Metab 2015;100:1316-24.

5. Machens A, Hinze R, Thomusch O, et al. Pattern of nodal metastasis for primary and reoperative thy-roid cancer. World Journal of Surgery 2002;26:22-8.

6. Reddy RM, Grigsby PW, Moley JF, et al. Lymph node metastases in differentiated thyroid cancer under $2 \mathrm{~cm}$. Surgery 2006;140:1050-4; discussion 4-5.

7. Zhang TT, Qu N, Hu JQ, et al. Mediastinal Lymph Node Metastases in Thyroid Cancer: Characteris-tics, Predictive Factors, and Prognosis. Int J Endocrinol 2017;2017:1868165.

8. Haugen BR, Alexander EK, Bible KC, et al. 2015 American Thyroid Association Management Guidelines for Adult Patients with Thyroid Nodules and Differentiated Thyroid Cancer: The American Thyroid Association Guidelines Task Force on Thyroid Nodules and Differentiated Thyroid Cancer. Thyroid 2016;26:1-133.

9. Adam MA, Pura J, Goffredo P, et al. Presence and Number of Lymph Node Metastases Are Associated With 
Compromised Survival for Patients Younger Than Age 45 Years With Papillary Thyroid Cancer. J Clin Oncol 2015;33:2370-5.

10. Qu N, Zhang L, Ji QH, et al. Risk Factors for Central Compartment Lymph Node Metastasis in Papil-lary Thyroid Microcarcinoma: A Meta-Analysis. World J Surg 2015;39:2459-70.

11. Zhang L, Wei WJ, Ji QH, et al. Risk factors for neck nodal metastasis in papillary thyroid microcarcino-ma: a study of 1066 patients. J Clin Endocrinol Metab 2012;97:1250-7.

12. Sun R, Zhang H, Liu K, et al. Clinicopathologic Predictive Factors of Cervical Lymph Node Metastasis in Differentiated Thyroid Cancer. Acta Otorrinolaringol Esp 2018;69:149-55.

13. Aydin Buyruk B, Kebapci N, Yorulmaz G, et al. An Evaluation of Clinicopathological Factors Effective in the Development of Central and Lateral Lymph Node Metastasis in Papillary Thyroid Cancer. J Natl Med Assoc 2018;110:384-90.

14. Hunt JP, Buchmann LO, Wang L, et al. An analysis of factors predicting lateral cervical nodal metastases in papillary carcinoma of the thyroid. Arch Otolaryngol Head Neck Surg 2011;137:1141-5.

15. Lee DJ, Lee KH, Kim JH, et al. Posterosuperior lesion

Cite this article as: Zhang TT, Qi XZ, Chen JP, Shi RL, Wen SS, Wang YL, Ji QH, Shen Q, Zhu YX, Qu N. The association between tumor's location and cervical lymph nodes metastasis in papillary thyroid cancer. Gland Surg 2019;8(5):557568. doi: 10.21037 /gs.2019.10.02 has a high risk of lateral and central nodal metastasis in solitary papillary thyroid cancer. World J Surg 2015;39:387-92.

16. Tessler FN, Middleton WD, Grant EG, et al. ACR Thyroid Imaging, Reporting and Data System (TI-RADS): White Paper of the ACR TI-RADS Committee. J Am Coll Radiol 2017;14:587-95.

17. Yeh MW, Bauer AJ, Bernet VA, et al. American Thyroid Association statement on preoperative imaging for thyroid cancer surgery. Thyroid 2015;25:3-14.

18. Dralle H, Machens A. Surgical management of the lateral neck compartment for metastatic thyroid can-cer. Curr Opin Oncol 2013;25:20-6.

19. Lee YS, Shin SC, Lim YS, et al. Tumor locationdependent skip lateral cervical lymph node metastasis in papillary thyroid cancer. Head Neck 2014;36:887-91.

20. Kwak JY, Kim EK, Kim MJ, et al. Papillary microcarcinoma of the thyroid: predicting factors of lateral neck node metastasis. Ann Surg Oncol 2009;16:1348-55.

21. Yuan J, Li J, Chen X, et al. Predictors of lymph nodes posterior to the right recurrent laryngeal nerve metastasis in patients with papillary thyroid carcinoma: A retrospective study. Medicine (Baltimore) 2017;96:e7908. 